\title{
Hermenéutica gadameriana y hermenéutica analógica en diálogo. Tópicos de encuentro y desencuentro*
}

\author{
Dialogue Between Gadamerian Hermeneutics and Analogical \\ Hermeneutics. Topics of Encounter and Disencounter
}

Hermenêutica gadameriana e hermenêutica analógica em diálogo. Tópicos de encontro e desencontro

\section{Dr. Noé Héctor Esquivel Estrada**}

\begin{abstract}
RESUMEN
El objetivo de este trabajo de investigación consiste en presentar dos versiones de hermenéuticas actuales, la de Hans-Georg Gadamer y la de Mauricio Beuchot, que, a la vez que nos permiten ver sus acercamientos y distanciamientos, abren posibilidades y caminos para una comprensión e interpretación más integral de la realidad. La delimitación de estas propuestas ha permitido seleccionar algunos rubros en los cuales se enlazan ambas perspectivas, tales como el diálogo, la ética y la cultura. También se señalan puntos de distanciamiento, donde el más relevante se centra en el recurso a la relación-separación entre la ontología y la metafísica. Para finalizar, nos aproximaremos a algunas reflexiones conclusivas.
\end{abstract} Palabras clave: hermenéutica, mediación, encuentro, desencuentro, diálogo, ética

Trabajo de investigación presentado parcialmente como Ponencia en el Primer Congreso Internacional de "Filosofía, Arte y Diseño. Diálogo en las fronteras", celebrado en la Universidad Autónoma del Estado de México (UAEMex), en consorcio con la Universidad de Guanajuato (México) los días 28, 29 y 30 de abril de 2015. Una segunda versión fue presentada como conferencia magistral en el marco del "Seminario de Filosofía Moderna y Contemporánea", realizado en la Facultad de Humanidades de la UAEMex en enero de 2019. Esta versión final es totalmente corregida.

"* Mexicano. Doctor en Filosofía por la Universidad Iberoamericana (Campus Ciudad de México). Profesor-Investigador del Instituto de Estudios sobre la Universidad de la (UAEMex). Contacto: noehectoresquivel49@gmail.com

ORCID: https://orcid.org/0000-0003-1863-192X 


\begin{abstract}
The objective of this research paper is to present two versions of current hermeneutics, that by Hans-Georg Gadamer and that of Mauricio Beuchot which, as they allow us to see their differences and similarities, also open up possibilities and paths for a more comprehensive understanding and interpretation of reality.. The delimitation of these proposals has allowed for the selection of some areas in which both perspectives are interwoven, such as dialogue, ethics and culture. The paper also discusses points of divergence, the most relevant of which is focused on the relationship-separation between ontology and metaphysics. The article ends with some final reflections and conclusions.
\end{abstract}

\section{RESUMO}

O objetivo deste trabalho de investigação consiste em apresentar duas versões de hermenêuticas atuais, a de Hans-Georg Gadamer e a de Mauricio Beuchot que, ao mesmo tempo que nos permitem ver suas aproximações e distanciamentos, abrem possibilidades e caminhos para uma compreensão e interpretação mais integral da realidade. A delimitação destas propostas permitiu selecionar algumas áreas nas quais ambas perspectivas se entrelaçam, tais como o diálogo, a ética e a cultura. Também são indicados pontos de distanciamento, onde o mais relevante está centrado no recurso da relação-separação entre a ontologia e a metafísica. Para finalizar, nos aproximaremos a algumas reflexões conclusivas.
Keywords: hermeneutics, mediation, encounter, disencounter, dialogue, ethics

Palavras-chave: hermenêutica, mediação, encontro, desencontro, diálogo, ética 


\section{Introducción}

El propósito de este trabajo de investigación consiste en presentar dos visiones de hermenéuticas actuales, la de Hans-Georg Gadamer y la de Mauricio Beuchot ${ }^{1}$, de modo que, a través de este recorrido, en un primer momento podamos reflexionar sobre algunos aspectos indicadores de preocupaciones comunes y que identificamos como acercamientos entre ambas propuestas; y, en un segundo momento, podamos atender a importantes distanciamientos, ocupando un lugar especial el de la fundamentación. En este caso, la hermenéutica filosófica gadameriana recurre a la ontología, mientras que la hermenéutica analógica apela indistintamente a la metafísica y a la ontología. Con lo cual se origina el problema de la fundamentación que, para nosotros, constituye el punto de separación más relevante de ambas hermenéuticas. Además, la forma de abordar esta temática nos permitirá descubrir otras posibilidades y caminos para una comprensión e interpretación más integral de la realidad.

Gadamer, en su texto Verdad y método. Fundamentos de una hermenéutica filosófica (1984), expone su proyecto de una hermenéutica filosófico-existencial en la que se involucran diversos aspectos que abarcan nuestra experiencia humana del mundo, lo que revela su riqueza y amplitud; es decir, desde esta perspectiva, se trasciende los límites impuestos por la metodología científica, la delimitación de la comprensión-interpretación de textos, la orientación teológica y jurídica como preceptivas del comprender, la crítica histórica y la distancia temporal, entre otros temas. Su punto de partida se enmarca en la experiencia del arte y la tradición histórica.

La finalidad de esta propuesta hermenéutica consiste en rastrear la experiencia de la verdad envuelta en la filosofía, el arte y la historia, sin limitarse a la justificación de la verdad del arte. Así lo formula Gadamer: "Intentaremos más bien desarrollar desde este punto de partida un concepto de conocimiento y de verdad que responda al conjunto de nuestra experiencia hermenéutica." (1984 25). En el siguiente párrafo,

Por razones de delimitación nos concentraremos en presentar solo algunos lineamientos que estructuran ambas propuestas, con el fin de tocar algunos tópicos de confluencia y de distanciamiento, con lo cual pretendemos cubrir la finalidad de este trabajo. 
el autor nos aclara cuál es el horizonte en el que se inserta su hermenéutica filosófica, dice:

... el modo como nos experimentamos unos a otros y como experimentamos las tradiciones históricas y las condiciones naturales de nuestra existencia y de nuestro mundo forma un auténtico universo hermenéutico con respecto al cual nosotros no estamos encerrados entre barreras insuperables sino abiertos a él (Id. 26).

Se trata de una conciencia crítica que, a la vez que forma parte de la tradición histórica, también asume un distanciamiento de ella debido al marco histórico-vital en el que vivimos comunitariamente.

Tratándose de la hermenéutica analógica, Beuchot, en la Introducción de su Tratado de hermenéutica analógica. Hacia un nuevo modelo de interpretación (2015), nos indica cuál es el objetivo de su propuesta y sus pretensiones:

... una hermenéutica analógica intenta abrir el campo de validez de interpretaciones cerrando el univocismo, pero también cerrar y poner límites al campo de validez de interpretaciones abierto desmesuradamente por el equivocismo, de modo que puede haber no una única interpretación válida, sino más de una, pero formando un pequeño grupo de interpretaciones válidas, según jerarquía, que puedan ser medidas y controladas con arreglo al texto y al autor (13).

Se descubre que la indicación de este procedimiento es mostrar el carácter medial de la analogía frente a los extremos opuestos propugnados por la univocidad y la equivocidad. Para nosotros, es comprensible que el recurso a la analogía tiene por finalidad marcar límites a la interpretación con la intención de "asegurar" su validez.

Si se reconoce a la hermenéutica como la ciencia y arte de la interpretación de textos, Beuchot recupera de la tradición el concepto de "sutileza", vista como el recurso para superar el sentido superficial y descubrir el sentido profundo del texto vinculado a la intencionalidad del autor, es decir, lo que el autor quiso decir. En este ejercicio de interpretación entran en juego, al menos, tres elementos: el autor, el texto y el lector, y es precisamente el recurso a la analogía lo que posibilita el equilibrio entre lo que el texto dice (univocidad) y la interpretación libre del lector (equivocidad). En definitiva, lo que ahora nos interesa 
es saber en qué consiste la analogía, pues reconocemos que ella ejerce la función medial entre puntos de vista radicalmente opuestos (univocidad-equivocidad). Dice el autor: “...lo análogo es lo que se predica o se dice de un conjunto de cosas en un sentido en parte idéntico y en parte distinto, predominando la diversidad" (Id.37-38).

Se ha de advertir que la obligada delimitación del estudio de estas propuestas nos ha permitido seleccionar algunos rubros en los cuales se enlazan ambas perspectivas, tales como el diálogo, la ética, la política y la cultura. Sin menoscabar que también se señalan puntos de distanciamiento, y el más relevante se centra en la fundamentación ontológica y la metafísica (como ya se mencionó). Pero el interés más importante para la hermenéutica analógica se perfila en atender cuál es la carga de objetividad y subjetividad en el ejercicio de comprensión e interpretación de la realidad, aspectos medulares que determinan la univocidad y la equivocidad de nuestra visión del mundo.

\section{Tópicos de encuentro}

En el horizonte de la hermenéutica gadameriana y la hermenéutica analógica nos encontramos con reflexiones y preocupaciones compartidas, tales como la inquietud por atender o resolver el problema acuciante que sobresale en el ejercicio hermenéutico al toparse con esta doble paradoja que sostiene posturas radicalmente opuestas: por una parte, aquella que afirma que solo hay una interpretación verdadera, lo que nos lleva, irremediablemente, a la aceptación del absolutismo, y, por otra, la que afirma que toda interpretación tiene el mismo valor, lo que consecuentemente desemboca en el relativismo. ¿Es posible encontrar mediación entre estas posturas? Precisamente, un tema medular de ambas versiones hermenéuticas es el de la mediación. Ésta no consiste simplemente en posibilitar que aquellas perspectivas antagónicas se acerquen y se respeten, sino en descubrir que todo conocimiento es conocimiento mediado; lo que nos permite reconocer que no hay un conocimiento inmediato, intuitivo, directo y absoluto de la realidad, pues este modo de acceder a ella le conferiría el carácter de inapelabilidad y, lógicamente, la obtención de una verdad incuestionable. La mediación significa aperturidad y receptividad del conocimiento del otro. Es dentro de este concepto de mediación que ubicamos el diálogo posibilitador de encuentro y apertura entre las concepciones de Gadamer y Beuchot. 
Con lo cual no se afirma que una u otra propuesta se encuentren ancladas en la situación paradojal, antes bien, ambas promueven el sentido medial, pero cada una desde su propia perspectiva particular (que es uno de los objetivos de este trabajo).

El carácter mediador del diálogo, al que en este momento nos referimos, es aquel que trasciende la confrontación excluyente de discursos, y que tiene su punto de partida, más bien, en la disposición y apertura a la visión del otro, con la posibilidad de que el otro tenga la razón. Actitud que no obliga a denegar los derechos y puntos de vista propios, sino a estar en disposición de aperturidad, que caracteriza el ser-diálogo. Somos "seres de diálogo", expresión común en el pensamiento de Gadamer.

Beuchot reconoce también que la hermenéutica gadameriana ejerce la función medial a través del diálogo. Dice:

Aquí se ve la pertinencia del diálogo para la hermenéutica, como insistía Gadamer, pero también para una hermenéutica analógica. En efecto, usualmente accedemos a la objetividad por medio de la intersubjetividad, esto es, mediante el diálogo. Presentamos nuestra interpretación a la crítica de los que conforman nuestra comunidad interpretativa o nuestra tradición hermenéutica, y es en ese diálogo vivo en el que se puede decidir si nuestra interpretación es válida o no, y cuál lo es (2015 60).

Se reconoce así al diálogo como esa actividad mediadora en el ejercicio de la hermenéutica analógica. El acercamiento a la objetividad de la interpretación se lleva a cabo mediante el acuerdo intersubjetivo, lo mismo que la validez de la interpretación se resuelve mediante el diálogo. Así lo ratifica su autor: "El único medio que tenemos de cribar la objetividad alcanzable y evitar lo más que se pueda la mera subjetividad es la intersubjetividad en el diálogo y la discusión con los demás de la misma comunidad o con los pertenecientes a otras comunidades. (Id. 57). La analogía funge, pues, como mediadora de extremos irreconciliables; por eso es pertinente, según el autor, el uso de la razón sutil o prudencial.

Beuchot comenta que el objetivismo y el subjetivismo ${ }^{2}$ tienen una relación directa con el tema de la verdad y de la realidad, y pueden

Tema que Beuchot, M. trata ampliamente en Hermenéutica analógica y ontología. México: CIDHEM, 2013. 
conducirnos a asumir tendencias radicales dentro de las actividades que realizamos en nuestra vida cotidiana, sea el estudio, la convivencia, el trabajo, etcétera, y, es aquí, precisamente, donde la hermenéutica analógica ejerce su tarea mediadora, así lo expresa:

No se trata ya de la pretensión de una verdad absoluta ni de, a causa de no poder conseguirla, desbarrancarse en el relativismo absoluto. Es alcanzable una verdad relativa, y ésta dentro de un relativismo relativo, o analógico. Ni pura objetividad ni pura subjetividad, sino la intermediación, el entrecruce de ambas, incluso con predominio de lo subjetivo sobre lo objetivo, lo cual es nuestra experiencia humana (2007 54).

La hermenéutica analógica hace aquí su intervención mediante la analogía de atribución, que es jerárquica o de "adecuación gradual." De igual modo, esta misma consideración sobre el carácter medial del diálogo la encontramos en la propuesta gadameriana, como preventivo para no arribar a equivocaciones, mediante lo que él llama el "algo" que debe orientar la interpretación, de lo contrario caeríamos en interpretaciones totalmente subjetivas o 'individuales'. Afirma Beuchot: "Pero entre lo equívoco y lo unívoco se encuentra la analogía. Lo equívoco es lo totalmente diverso, lo no conmensurable con otro; lo unívoco es lo totalmente idéntico. Pero lo análogo es lo en parte idéntico y lo en parte diverso" (Id.38).

Beuchot, en algunos de sus trabajos, nos diseña un breve recorrido acerca de distintas corrientes hermenéuticas y de hermeneutas que pueden ser denominados "tradicionales", por darles un nombre, entre los que ubica a Gadamer y Ricoeur, y los posmodernos o "radicales", entre los que sobresalen Foucault, Derrida y Vattimo, por mencionar algunos. Frente a esta situación se pregunta: ¿qué aporta la hermenéutica analógica a la historia general de la hermenéutica? El autor sostiene que: "Pues bien, la hermenéutica analógica es un intento de ir más allá de la hermenéutica metafórica de Ricoeur; pero, sobre todo, para mediar entre las hermenéuticas univocistas y equivocistas que proliferan en la actualidad" (Id. 18). Así, el quehacer fundamental de la analogía no consiste solo en respetar las diferencias, sino en la búsqueda de las semejanzas que proporcionen cierta objetividad y universalidad. Si la interpretación se guía solo por las identidades arribamos a los totalitarismos, pero si reconoce únicamente las diferencias, entonces no 
hay verdad sino relativismo o equivocidad. El mismo Ricoeur, comenta Beuchot, con el uso de la metáfora, se inclina más a la equivocidad, por lo que hace falta el recurso a la metonimia que, como figura de significado, tiende a la univocidad, estableciéndose así un cierto equilibrio en la interpretación. "En efecto, hay una analogía metafórica, que es la de proporcionalidad impropia; pero también hay una analogía metonímica que es la de proporcionalidad propia y la de atribución, según se veía en la tradición." (Id.21). La propuesta de la hermenéutica analógica consiste en conjuntar o construir el puente entre la metáfora (equivocista) y la metonimia (univocista). La interpretación debe tomar en consideración tanto el sentido alegórico-simbólico como el sentido literal, salvándose así las polarizaciones. Las posturas antagónicas excluyentes las encontramos en toda la historia de la filosofía, desde sus orígenes hasta la actualidad.

Beuchot también reconoce que Gadamer, en su exposición hermenéutica, hace uso de la analogía, así lo consigna en su obra: "Más recientemente, Gadamer ha sido uno de los que ha rescatado la analogía, y precisamente en la hermenéutica. Lo ha hecho indirectamente, ya que propone como esquema de la hermenéutica la phrónesis aristotélica o prudencia, la cual es una virtud sumamente analógica" (Id. 35). De igual manera reconoce que Ricoeur necesita del uso de la analogía para la exposición de su pensamiento:

Directamente ha usado la analogía Paul Ricoeur, y también en la hermenéutica. La lleva a su discurso desde que estudia los símbolos, principalmente los mitos. Allí el conocimiento por analogía es el que se requiere, ya que los símbolos siempre hablan de manera oculta. También la usa en su estudio sobre la metáfora, que es una de las formas de la analogía. Y, de manera especial, en su reconstrucción del sujeto, ya que ve al sí mismo como otro, y emplea la analogía de la acción para hacer ver que el sujeto habla y actúa, por lo que es sujeto de narración, y, además, es sujeto de imputación moral, esto es, de responsabilidad ética (Id. 36).

Ya hemos mencionado por qué la necesidad de la mediación en el conocimiento, lo mismo que la función mediadora de la analogía; pero, el puente medial de la analogía no es nada sencillo o simplista, como bien lo califica Beuchot cuando se la limita a ser "medio entre dos extremos", sino que tiene que cumplir con el requisito de ser vín- 
culo mediador y equilibrado entre los extremos excluyentes, pues el punto medio matemático en la interpretación hermenéutica es inexistente, siempre nos inclinamos más a un lado que a otro. Reconocemos así el carácter humano de la comprensión hermenéutica.

\section{a) Lenguaje - diálogo}

Hablamos del sentido existencial del lenguaje. El lenguaje, como podremos ver, es una forma de vida que tiene su auténtico ser en el diálogo (conversación), en el ejercicio del mutuo entendimiento. Según Gadamer: "Todas las formas de la comunidad de vida humana son formas de comunidad lingüística, más aún, hacen lenguaje. Pues el lenguaje es por su esencia el lenguaje de la conversación" (1984 535). Sin comunidad de vida, sin conversación, sin entendimiento, no hay lenguaje. En el diálogo con-vivimos, nos entendemos y somos capaces de consensos a favor de la vida. Las formas de entendimiento artificiales no son lenguaje porque no son formas de vida, razón por la que se les puede considerar solo como instrumentos de entendimiento común. Dentro de estas formas de entendimiento artificiales, bien cabrían todas las expresiones de la racionalidad instrumental "entrometidas" en el ámbito de la comunicación humana, que si bien logran alcanzar los fines y utilidades determinados, no por ello pueden ser reconocidas como formas de vida constitutivas de la vida humana, donde ésta es sustancialmente una forma de vida compartida. Conversación-Convivencia es expresión plena de la vida humana.

En la relación lenguaje-objeto, propia de la objetivación científica, se descubre solo una de tantas relatividades que abarca la relación lenguaje-mundo, pero de ninguna manera ésta puede ser totalizadora y absoluta. En la experiencia lingüística del mundo hablar no significa volver las cosas disponibles y calculables, sino establecer una relación vital con ellas, es decir, propiciar una experiencia humana del mundo, lo que en este campo llamamos "experiencia hermenéutica del mundo". Así, el mundo de la experiencia, de la vivencia, de la interioridad no puede quedar atrapado dentro del campo del conocimiento-sensible-empírico-científico, fuente solo de verdades objetivas.

Dentro del horizonte de la experiencia hermenéutica es manifiesta la importancia que Gadamer concede al lenguaje que escapa a toda instrumentalización. Nosotros mismos somos lenguaje en-relación- 
con. El lenguaje es el lugar de la conversación y de la convivencia. La dificultad de entender la comprensión lingüística en estos términos encierra dos alternativas: por una parte, ella misma permite la confusión y el malentendido, pero, por otra, también ella abre la posibilidad de su superación, pues el lenguaje es diálogo. El lenguaje no puede quedar atrapado en las redes del engaño, de la ideología, de la objetivación, del monólogo, del malentendido. Por eso, dice Gadamer: "Es preciso buscar la palabra y se puede encontrar la palabra que alcance al otro, se puede incluso aprender la lengua ajena, la del otro. Todo esto puede hacerlo el lenguaje como lenguaje" (1992 352). Lo que nos habla no solo del uso adecuado de los términos para lograr un buen entendimiento, sino de la posibilidad inherente al lenguaje de "alcanzar al otro". Ello exige salir de sí mismo, pensar al otro y volver sobre sí mismo como otro. Términos propios de la conversación y de la convivencia. Lugares comunes tanto de la hermenéutica gadameriana como de la analógica.

Reconocemos que uno de los aspectos sustantivos, quizás el más importante, de la hermenéutica gadameriana es el diálogo, la conversación. Para el filósofo de Marburgo, la verdadera conversación tiene su propia voluntad, es decir, no depende de la intención de los dialogantes, antes bien ellos son llevados por la conversación misma. La verdadera conversación no conoce previamente su término, recorre caminos desconocidos; en cambio, una conversación determinada por la intención de los dialogantes sabe hacia dónde se dirige y espera llegar al fin preestablecido. Hablamos así de una forma de manipulación de la conversación. La conversación se desenvuelve a través de preguntas y respuestas, argumenta en paralelo, entra en la búsqueda común del sentido y pretende arribar al acuerdo. Aspectos constitutivos del diálogo que podemos testificar en la vida y obra de este filósofo.

Hemos dicho que un rasgo característico de la verdadera conversación consiste en dejarse envolver por ella. Ella es la que nos guía. Otro atributo de la auténtica conversación es la disposición a dejarse decir algo; no basta el emisor y el receptor, sobre ellos está la disposición a "conversar", es decir, abrirse a la escucha del otro, pues eso es conversar; muestra de ello es lo que sucede en una auténtica conversación cotidiana, es decir, cuando intercambiamos nuestros pensamientos, nuestras inquietudes y dudas, sin reservas y engaños. Esta forma de 
conversación tiene que ver con la verdad. En el apartado "De la contribución de la poesía a la búsqueda de la verdad”, Gadamer dice al respecto:

¿Qué es lo que está realmente presupuesto cuando uno se deja decir algo? Es claro que la condición suprema para ello estriba en no creer "saberlo mejor todo" sino en ser capaz de cuestionar aquello que se cree saber. De hecho, la posibilidad de la conversación descansa sobre el juego de arrojarse mutuamente preguntas y respuestas (2001 112).

En esta dinámica, la conversación no acepta respuestas últimas, pues cada respuesta es generadora de nuevas preguntas, lo que recibe el nombre de "carácter hermenéutico del hablar". La hermenéutica del diálogo no arriba a conclusiones finales, definitivas, todas ellas son provisionales. En el intercambio de palabras ambos dialogantes se enriquecen ${ }^{3}$. El juego de la conversación se ve envuelto por un sentido ético: de apertura, de enriquecimiento, de búsqueda común y de acción solidaria. La conversación y la ética vienen a ser "formas-constitutivas" de nuestro ser y actuar en el mundo y con el mundo.

El diálogo no se agota en el rastreo de un sentido en el que podamos coincidir con la intención de confirmar lo que ya sabemos, sino en el principio de dejarse decir algo. Ángel Gabilondo, quien hace la Introducción al texto de Gadamer Estética y hermenéutica, comenta al respecto: "Dado que estamos dispuestos a semejante dejarnos decir algo, no sabemos ya todo mejor de lo que cabría decirse y necesitamos sumergirnos en algo y hacerlo con alguien, lo que en modo alguno se reduce a introducirse en los sentimientos del otro para adivinar su vida psíquica" ( $c f$. Gadamer 2001 15). Como se puede advertir en este comentario, por una parte el juego de la relación vital es de naturaleza dialogal, intersubjetiva, sobre algo; y, por otra, la intención del autor es alertar a los dialogantes para no quedar atrapados bajo las redes del psicologismo o del objetivismo. Actitud pretensiosa o manipuladora que no da cabida a la relación hermenéutica. El "dejarse decir algo" se resuelve discursiva-

Otra forma de comunicación totalmente diversa de ésta es la que se lleva a cabo mediante el lenguaje de la poesía, en ella no preguntamos qué es lo que se nos quiere decir, sino que el lenguaje poético "se yergue ahí en sí"; solo en esta dimensión se entiende y se experimenta la poesía. La verdad de la poesía se cumple en sí misma y no precisa de una verificación fuera de ella. 
mente en la conversación que busca la "develación" del ser (ocultamiento-desocultamiento). El diálogo no es ni instrumento ni método. Somos conversación, diálogo infinito de la propia finitud; diálogo circundante que se desenvuelve a través de preguntas y respuestas. El diálogo es dispositivo y apertura permanente hacia la alteridad. El consenso no es una expresión de triunfo por parte de alguno de los dialogantes, sino interpretación común del mundo. En este encuentro intersubjetivo acontece la verdad. Los dialogantes no solo buscan decir y escuchar algo, sino su conversación es expresión de su ser, de su quehacer y de su vida. En la conversación nosotros mismos somos ese decir.

Antes de toda reflexión impositiva debe imperar el respeto y el reconocimiento del otro. El intercambio, la apertura, la sinceridad son condiciones de posibilidad indispensables en el ejercicio de una auténtica conversación. En términos de Gadamer: "Pero quizás sea ése el mensaje consolador de la hermenéutica, incluso en tiempos de modernidad acelerada y de sus vicisitudes en el conocimiento: la comprensión es posible más allá de distancias y diferencias, siempre que los dialogantes, sean quienes sean, se esfuercen por comprender" (2004 15).

Comprender va más allá de un acto de conocimiento, es un "dispositivo" de interrelación capaz de franquear barreras culturales, educativas, políticas, religiosas, generacionales, etcétera. Comprender es estar-en-disposición de compartir: dar y recibir, más allá de nuestras propias convicciones. Disponernos y entrar en conversación, con la intención de comprender, es entrar en la aperturidad hacia el otro. Para nuestro autor, el diálogo es el camino de acceso a la comprensión en situaciones problemáticas. La discusión ha de estar animada por la buena voluntad del entendimiento mutuo, jamás por el interés de vencer en la discusión.

De ningún modo el diálogo es un discurso persuasivo (retórico), pues quien intenta persuadir supone tener la razón $n^{4}$. El diálogo es un

\footnotetext{
$4 \quad$ Cuando Gadamer trata el tema de la relación entre la ética y la retórica, comenta que no se puede valorar a la retórica de manera negativa ni peyorativamente, pues es un medio de conversación, de persuasión. La ética misma es retórica, debido a que no puede proceder a la manera de las ciencias exactas. Lo negativo de la retórica es cuando se utiliza como recurso persuasivo engañoso, apartándose así de su sentido ético. Una revaloración de la retórica nos llevaría a ubicarla en el mismo campo de la phronesis. Así
} 
discurso de reconocimiento de la diferencia en la búsqueda de un acuerdo común. Desde esta perspectiva arribamos a una conclusión importante: no se trata solo de discursos, sino de un proceder, de una praxis, que nos acerque al bien común. Comenta Gadamer: "Son más preferibles las personas que se mantienen en una posición críticopragmáticas que los que se engañan con estar en posesión de verdades absolutas. (...) Pero lo que efectivamente nos concierne y de verdad nos importa es lo que hacemos de forma correcta, o lo que hacemos de forma errónea" (2010 56). En tal sentido, hemos de reconocer que el diálogo encuentra su realización en el actuar humano (praxis) y se considera auténtico cuando no coacciona o genera injusticia en la relación con el otro. Imponer la razón propia antes que escuchar las razones del otro, eso es una forma de injusticia. El auténtico diálogo no obliga a renunciar a las propias convicciones ni a la propia verdad, pero exige apertura hacia una verdad más convincente, a riesgo de que ésta no sea la mía sino la del otro.

El mismo Beuchot comenta que, cuando Gadamer aborda el tema de la aplicación como ejercicio constitutivo del quehacer hermenéutico, lo que busca es mostrar la conjugación que se da entre la teoría y la praxis; toda comprensión es aplicación, lo mismo que toda interpretación es comprensión y toda interpretación es aplicación; comprensión-interpretación-aplicación constituyen parte integral del círculo hermenéutico, no pueden prescindir uno del otro. En esos mismos términos se refiere Beuchot al hablar de la hermenéutica docens y de la hermenéutica utens para establecer la relación entre teoría y praxis; dice: “...en el caso de la hermenéutica, como en el de la lógica, dada su amplitud, puede tener el doble aspecto de ser teoría y práctica a la vez. Pero es primordialmente teórica, y secundaria o derivadamente práctica porque el que pueda ser práctica se deriva de su mismo ser teórico" (2015 23).

lo entiende Gadamer: "De hecho la retórica pertenece fundamentalmente a la phronesis, es una forma de la phronesis o de la sabiduría práctica, al igual que la ética. Por eso yo veo en la ética esencialmente un desarrollo de la phronesis, de aquella sabiduría que consiste en buscar el común acuerdo o consenso con total respeto del otro" (Gadamer, Hans-Georg. El último dios. La lección del siglo XX. Un diálogo filosófico con Riccardo Dottori. Barcelona: Anthropos/UAM (Cuajimalpa), 2010, 64). Si bien el interés primario de la retórica está en el carácter persuasivo de la verdad encontrada, no por eso se reduce a ello. En tal caso se identificaría con la voluntad de poder, pero ¿por qué no ver en ella también la voluntad de verdad? 
b) Diálogo - ética

El proceso dialogal no encuentra su realización plena en el entendimiento común a nivel intelectual, sino en las aplicaciones prácticas que se resuelven en un nivel comunitario, cuando se tiene como fin el bien común. De este modo, el diálogo y el consenso tienen implicaciones ético-sociales, pues privilegian el aspecto comunitario sobre el nivel individual. Así lo entiende Gadamer: "El grado en que el otro comprende lo que yo quiero decir aparece en su versión. Lo comprendido pasa así desde la indeterminación de su sentido a una nueva determinación, que permite comprender o malentender. Este es el verdadero proceso del diálogo: el contenido se articula haciéndose un bien común" (1992 25). El otro aspecto relevante del diálogo, al que aquí se refiere el autor, es que el comprender no es impositivo en vistas solo a la "verdadera comprensión", por lo que queda abierta además la posibilidad del malentendido, pero sin quedarse atrapado en él.

El diálogo, para Gadamer, no es una acción ni, mucho menos, un instrumento. Su esencia radica en nuestra propia naturaleza: somos esencialmente diálogo. Somos diálogo viviente. La conversación cotidiana es también un claro ejemplo de este modo de proceder habitual, en el que cada hablante quiere hacer valer sus propias razones y sustentar su verdad en sus convicciones, pero sin intención de engañar. Sin embargo, y a pesar de todo, esta disposición también ha de estar sujeta a la búsqueda y al enjuiciamiento de la mejor razón.

La reiterada importancia que Gadamer concede al diálogo no lo exime de la crítica, pues lo sustancial de la crítica no consiste en tolerarla, sino en permitirla y propiciarla. Así, toda reflexión sobre una situación social problemática debe sustentarse en un dispositivo dialogal en el que se conjuguen la posibilidad de la crítica y la pretensión de consenso. En la convivencia social (conversación es convivencia) se entrecruzan posturas culturales, ideológicas, políticas y religiosas, dando lugar al reconocimiento intersubjetivo y a la capacidad de consenso. Solo las luchas ideológicas son excluyentes, no dan cabida al consenso. Para Gadamer, es la phronesis, la sabiduría, la que ha jugado un papel fundamental en la lucha contra las ideologías. Phronesis es también diálogo. Nuevamente diálogo y ética se encuentran entrelazados. 
Hemos dicho que el diálogo es conversación. Pero la conversación no puede restringirse al intercambio de palabras que realizan los dialogantes. El núcleo de la conversación es el entendimiento mutuo, es decir, es la experiencia fundamental de la convivencia humana. Sin embargo, advirtamos que la conversación no desemboca necesariamente en el consenso; por el contrario, ésta significa apertura libre a la dimensión del otro, dando lugar al disenso, donde la coincidencia consiste en haber compartido algo razonable. Por eso la conversación está inexorablemente ligada a la escucha. La palabra pronunciada pertenece al que la oye, ya no es propiedad de quien la pronuncia; cumple con su misión al ser entregada a los oyentes. La palabra hablada encuentra su plenitud en la pluralidad de interpretaciones en el silencio de quienes escuchan. La palabra llama a la colaboración de los oyentes en la libertad. Toda palabra pide respuesta. De donde se infiere la responsabilidad de la palabra pronunciada y escuchada.

En el artículo "La incapacidad para el diálogo" (1971), Gadamer señala algunos obstáculos que imposibilitan el diálogo en el mundo contemporáneo. Entre los que sobresalen a) la tendencia a la monologización, homogeneización y homologación de la conducta humana, es decir, la pretensión de hacer que todos pensemos y actuemos del mismo modo; b) el modo de pensar técnico-científico, que pretende también la estandarización; c) la experiencia de la auto-enajenación o soledad de vida; d) el rechazo explícito a una auténtica voluntad de consenso, y e) el repudio a los mentirosos disfrazados de la vida pública. A pesar de estas barreras, dice: "La capacidad para el diálogo es un atributo natural del ser humano. Aristóteles definió al hombre como un ser dotado de lenguaje, y el lenguaje se da solo en el diálogo" (1992 203). Sin la práctica de la conversación el lenguaje se ve reducido a un espectro. Pero el diálogo no puede limitarse a la capacidad de habla, sino a algo más que, ahora, es necesario pensar. Nos referimos a esta disposición de apertura, de reciprocidad y de respeto hacia el otro (inherentes al habla misma), en la que los dialogantes se vean envueltos por la conversación con la misma posibilidad de consensuar o diferir. El diálogo es así el vehículo que conduce a los dialogantes a la profundidad de la comunión humana. En este intercambio comunicativo se hace patente tanto factibilidades como resistencias. El diálogo auténtico, llevado a cabo desde perspectivas de mundos distintos, de 
concepciones y experiencias diferentes, enriquece la conversación, la convivencia. Habrá que limpiar la idea de que la diferencia es un impedimento para la conversación y será necesario despojarla de la carga de los prejuicios negativos. Gadamer, refiriéndose a Sócrates como uno de los filósofos carismáticos del diálogo, dice: "Consideró un principio de verdad que la palabra solo encuentra confirmación en la recepción y aprobación por el otro y que las conclusiones que no vayan acompañadas del pensamiento del otro pierden vigor argumentativo" (Id. 205). El diálogo no pretende opacar o disminuir la individualidad, ni los puntos de vista particulares y los malentendidos, sino arribar a la generalidad característica de la razón común, lo que llamamos "acuerdo" o "consenso". Así, nuestro autor le asigna a la conversación una fuerza transformadora. ¿Qué quiere decir esto? Que en la conversación los dialogantes se transforman, ambos encuentran al otro y se encuentran a sí mismos en el otro. En esto radica el encuentro auténtico con el otro ${ }^{5}$.

La forma de ver el mundo y de relacionarnos con él se transforma de manera sustancial si asumimos como punto de partida el encuentro con el otro. Comenta Mardones: "Y uno de los logros fundamentales del encuentro y la comunicación con el otro es la solidaridad, el desinter-és y la "proximidad del prójimo", más que la coincidencia con uno mismo (Lévinas). Es decir, nos encontramos en la circunstancia originaria del acontecimiento ético" (172). El diálogo en su esencia asume la connotación de encuentro. Y encuentro significa también, y quizás primordialmente, verse en el rostro del otro. El encuentro con el otro me muestra mi propio ser, mi propio rostro. Sin tal encuentro no hay posibilidad de descubrirnos el rostro, de vernos cara a cara.

El diálogo se origina y desarrolla en el proceso de autocomprensión. El proceso dialogal reconoce su inicio en el momento de la autocomprensión, es decir, en primer término debemos comprendernos a nosotros mismos antes de comprender a los demás; solo si somos capaces de entendernos estaremos en disposición de comprender al 
otro y lo otro. A esto llamamos auténticamente "autocomprensión". Gadamer insiste en que:

No es que no entendamos al otro, sino que no nos entendemos a nosotros mismos. Precisamente cuando tratamos de entender al otro, tenemos la experiencia hermenéutica de que tenemos que romper en nosotros una resistencia, si es que queremos escuchar al otro como el otro que es. Esto es realmente una radical nota básica de todo existir humano, y es algo que domina incluso lo que solemos llamar nuestra autocomprensión (2001 358).

El proyecto humano encuentra su facticidad y realización en el reconocimiento del otro. Es imposible vivir la existencia humana de otro modo o encerrado en sí mismo. En estos términos, afirmamos que el diálogo no es solo un proceso comunicativo, como generalmente se lo entiende, sino un modo indispensable de vida compartida. Solo en el camino del reconocimiento mutuo se encuentra la posibilidad de vida ética, no como aceptación de normas, sino como modo de ser y habitar en el mundo. El modo de compartir dialogal nos ubica en el modo de ser ético-humano. Por ello el carácter vivo del lenguaje encuentra perfectamente su realización en el diálogo. Si somos seres de lenguaje, somos seres de diálogo y seres humanamente éticos. De este texto podemos inferir una consecuencia radical para la existencia humana: su imposibilidad de existir o sobrevivir sin la autocomprensión y la relación con el otro. Somos seres de naturaleza dialogal-compartida, lugar donde se realiza la existencia humana.

Hemos dicho que uno de los aspectos fundamentales del quehacer hermenéutico es el diálogo o conversación. La conversación auténtica se concretiza en el consenso. Por eso una implicación ética del diálogo es la apertura no solo para entender al otro, sino para reconocer la posibilidad de que el otro tenga la verdad. Así se reafirma el carácter ético del diálogo. Asegura Gadamer:

La conversación no es posible si uno de los interlocutores cree absolutamente en una tesis superior a las otras, hasta afirmar que posee un saber previo sobre los prejuicios que atenazan al otro. El mismo se implica así en sus propios prejuicios. El consenso dialogal es imposible en principio si uno de los interlocutores no se libera realmente para la conversación (1992 117). 
Con el interés de ejemplificar la necesidad del diálogo y de la convivencia entre los seres humanos, Beuchot menciona el multiculturalismo - o interculturalidad o mestizaje ${ }^{6}$ - como un fenómeno que nos ha alcanzado y que exige un tratamiento especial y responsable; ya no es suficiente con reconocer la diversidad de culturas que no se tocan, que son ajenas, sino es necesario reconocer cómo interactúan y se relacionan con la posibilidad de establecer convivencia entre ambas. Comenta el autor que la hermenéutica analógica abre esta posibilidad de encuentro en el reconocimiento de la diversidad, "pero sin perder la universalidad" (2007 108)7 . Aquí se conjugan la identidad y el cambio, sin privilegiar una u otro. Razón por la cual considera importante la participación de la hermenéutica analógica.

En este diálogo intercultural, la ética no puede ser un fenómeno ajeno o excluido, sino más bien incluyente en este intercambio común. Así lo expresa:

Aprendemos de las otras culturas, en el sentido de adquirir unas cosas y rechazar otras. Hay pugna de ideas y valores. Con ello se tiene que llegar a una ética multicultural, inclusive intercultural. Y ella es producto de la comunicación entre culturas, la cual no es fácil, ya que hay que evitar, como pedía Taylor, entender a los otros como nosotros (hay que tratar de entenderlos como ellos se entienden, y esto se alcanza solo analógicamente) (Id. 114-115).

Es decir, partimos de la necesidad del reconocimiento de la diferencia, pero sin menoscabar la propia identidad. En el ámbito de la ética es importante el reconocimiento de mínimos consensuados que posibiliten la convivencia, pues los máximos son difíciles de consenso. El recurso para alcanzar este intercambio respetuoso es el diálogo en sentido pleno, es decir, no consiste en un simple intercambio de pala-

\footnotetext{
$6 \quad$ La ampliación de esta temática la lleva a cabo Beuchot, M. en Interculturalidad y derechos humanos. México: UNAM/siglo XXI, 2005.

7 En esta misma página nos aporta una noción de cultura: "Si recordamos que la noción de cultura proviene de colere, cultivar, veremos que, primariamente, alude a una adaptación a la naturaleza. (Algunos quieren derivarla de cultum, culto). Se contraponían natura y cultura, y la segunda era para cultivar y domesticar a la primera. Pero también para hacer convivir al hombre con los demás, por eso abarcaba bienes materiales, instituciones, valores y normas, derechos y leyes, signos y símbolos. Es decir, en el hombre se reconoce un aspecto biológico y un aspecto simbólico, tan determinante como el anterior (o más)".
} 
bras o ideas, sino en la búsqueda de un entendimiento común. Afirma Beuchot: “... la exigencia, más fuerte, casi ideal, de alcanzar un horizonte o trasfondo de significado compartido, a saber, llegar mediante el diálogo a comprender a la otra cultura no solo como nosotros la comprendemos, sino incluso como ellos se comprenden, pues de otra manera no habremos superado el peligroso etnocentrismo" (Id. 120).

Beuchot nos comenta que en la enseñanza educativa la hermenéutica analógica ha servido para encausar el multiculturalismo. "Un multiculturalismo analógico, que rebase la sola coexistencia pacífica del multiculturalismo, y que alcance a promover la interacción entre las culturas que entran en diálogo educativo" (2007 96). En los mismos términos, bien puede recuperarse la idea del diálogo gadameriano: no se trata simplemente de tomar en cuenta lo diferente que tiene la otra cultura, sino de descubrir aquellos elementos que posibiliten el encuentro entre ambas. Para este diálogo intercultural se requiere aperturidad, respeto y disposición a reconocer la aportación de la otra cultura para la construcción de una verdad compartida.

Otro recurso más al que el autor apela para conectar el quehacer de la analogía con el diálogo terapéutico, es el psicoanálisis (Beuchot 2006b). Desde sus orígenes, reconoce que la labor freudiana fue analógica después del abandono de su preocupación positivista, científica. Debido a la conexión que el autor establece entre hermenéutica analógica y diálogo terapéutico (psicoanálisis) es que centraremos la atención en este asunto. Comenta al respecto:

Cada vez cobra más fuerza el estudio y análisis de la relación entre analista y analizado, en la línea de Ferenczi, como un diálogo. Y el diálogo es de lo más hermenéutico, pues es la interpretación mutua, necesaria para la adecuada comunicación entre los dialogantes. En la visualización del análisis como un diálogo, el analista interpreta al analizado, pero también éste a aquél. Entre ambos dialogantes crean un espacio en el que las interpretaciones llevan al insight. Y es como el analizado avanza en su cura (2007 74).

Así, el autor reconoce la aportación que hace la hermenéutica analógica para establecer el equilibrio entre la postura radical del analista -rígida, univocista - y la visión caprichosa y arbitraria del analizado, que lo conduce a un relativismo absoluto y caótico. 
Se libra una guerra intestina entre las tendencias y pulsiones del hombre. Si se es univocista, se inhibirán las pulsiones; si se es equivocista, se dará libre pábulo a éstas; en ambos casos hay conflicto, situación mala; en cambio, si se equilibra proporcionalmente, se obtendrá un buen funcionamiento de la psique. El yo es acosado por las pulsiones del ello y las represiones del superyó. Se requiere un equilibrio pulsional y un equilibrio entre las fuerzas del ello y del superyó con respecto al yo (Id. 78-79).

En el diálogo terapéutico impera, precisamente, la incapacidad inconsciente para la conversación, por eso se requiere del experto que funja como facilitador del diálogo, propiciando que el paciente descubra cuáles son las fuerzas que le impiden dialogar. Con esta ayuda supera dicha incapacidad y restablece las condiciones para el ejercicio normal de la conversación.

En la conversación familiar se nos presenta directamente esta doble posibilidad: a) la incapacidad para dialogar y b) la conversación auténtica. La incapacidad para el diálogo se origina en la negación para reconocer tal incapacidad. La apelación a ésta, dice Gadamer, se exterioriza de la siguiente manera: "Suele ofrecer por el contrario la peculiaridad de alguien que no ve esta incapacidad en sí mismo, sino en el otro. Uno dice: contigo no se puede hablar" ( $c f$. Beuchot 2007 209). La consecuencia de esta actitud es el desconcierto, la inseguridad, el malestar y, finalmente, la cerrazón. La incapacidad para el diálogo con el otro no es más que el reflejo de la propia incapacidad para abrirse a los demás. Las reacciones que se siguen de esta actitud son generadas por uno mismo, no por el otro. El no oír y el malentender son expresión del ensimismamiento, de la búsqueda de intereses particulares y de impulsos y deseos egoístas. Tales situaciones constituyen las circunstancias objetivas o subjetivas que impiden la conversación. La esencia del lenguaje es, precisamente, lo opuesto a esa actitud; dice Gadamer, "es hablar-a-alguien y contestar-a-alguien" (cf. Id. 210). Lo que revela la naturaleza de la conversación.

Así, sobre los asuntos referentes a la psicología y al psicoanálisis, Beuchot reconoce los aportes que la hermenéutica analógica hace a la antropología filosófica, apuntando a una visión más completa e integradora del hombre. 
Reconocemos que es la experiencia hermenéutica la que nos hace vulnerables al diálogo, es decir, a vivir la experiencia de nuestro propio reconocimiento, de nuestra existencia y del reconocimiento y existencia del otro. No se trata, por tanto, de reducir la hermenéutica a un recurso metodológico para la comprensión de las ciencias sociales, sino de una experiencia humana de nuestro propio ser, del mundo y del otro. Experiencia un tanto trágica, como lo es también en su esencia la experiencia ética.

Finalmente, otro tema en el que se encuentran coincidencias entre Gadamer y Beuchot es en el "círculo hermenéutico del todo y las partes", así denominado por Gadamer; aquí éste señala que la parte debe entenderse dentro de la totalidad y la totalidad se explica a partir de cada una de las partes. Beuchot explica este círculo hermenéutico mediante los términos "individual" y "general"; lo individual se refiere a un texto en concreto, mientras que lo universal nos remite al contexto. Apunta: "Sobre todo, el círculo hermenéutico se da en la relación de lo universal y lo particular, que es precisamente la del texto, que es algo individual, con su contexto, que es algo universal: el sensus communis de la sociedad o cultura" (2007 54).

\section{Tópicos de distanciamiento entre ambas propuestas}

Ciertamente existen algunos aspectos que diferencian a la hermenéutica gadameriana de la hermenéutica analógica, pero el punto en el que queremos enfocarnos, en este momento, es el que se refiere a la ontología y a la metafísica, que es en el que, descubrimos, se agudiza este desencuentro.

Uno de los temas más controversiales entre la hermenéutica gadameriana y la hermenéutica analógica se presenta cuando Beuchot afirma que la hermenéutica de Gadamer se orienta hacia la des-ontologización. Veamos en qué consiste tal des-ontologización y cuál es el sentido que Beuchot le asigna. Aun cuando consideramos que, en lo tocante a este punto, más que oposición hay concordancia, pues ambas hermenéuticas reconocen una base ontológica, como intentaremos explicarlo un poco adelante. Sin embargo, el comentario del autor es el siguiente:

En la actualidad se ha dado un proceso de des-ontologización de la hermenéutica. Se le ha querido desvincular de toda fundamentación ontológica o metafísica dado que se proclama la ausencia de 
fundamentos y un relativismo muy extremo. Por eso es necesario recuperar para la hermenéutica su relación con la ontología. Y ésta no puede ser más que de fundamentación (2015 99).

Esta perspectiva de fundamentación ontológica, consideramos, también está presente en la hermenéutica gadameriana. El mismo subtítulo de su obra Verdad y método. Fundamentos de una hermenéutica filosófica así lo confirma. Pero, posiblemente, el problema surge cuando Beuchot se refiere a la ontología y a la metafísica en los mismos términos. Porque, ¿ existe diferencia entre ontología y metafísica? Precisamente, sobre este asunto nos detendremos a reflexionar, pues en el apartado que Beuchot titula "La metafísica y la hermenéutica de Gadamer" (2015 100-103) es donde encontramos este distanciamiento. Es verdad que ambos hablan de la necesidad de una fundamentación para la hermenéutica, pero ¿será lo mismo la fundamentación ontológica que la metafísica? ¿Cuál puede ser la diferencia? La fundamentación ontológica exige que la hermenéutica haga siempre referencia al ser; en cambio, la fundamentación metafísica conducirá a la hermenéutica a comprensiones e interpretaciones últimas o definitivas, cosa que no se sigue de la fundamentación ontológica.

Beuchot, al hablar del fundamento metafísico de la hermenéutica, apela al aspecto semiótico de la verdad y afirma que ésta no puede restringirse al aspecto sintáctico y pragmático, dice: "Mas no parece ser posible ni legítimo que se deseche esta dimensión. En efecto, al interpretar no basta ver la corrección (sintaxis), ni la validez (pragmática); hay que ver la adecuación (semántica). Porque la hermenéutica examina una correlación" (2015 101). Con el propósito de ampliar su exposición sobre la necesidad de esta fundamentación metafísica, continúa con el análisis del sentido de correlación y recupera un artículo de Juan Pegueroles titulado: "El ser y la verdad de la hermenéutica de Gadamer" ${ }^{\text {. }}$. Concluye la reflexión indicando que la hermenéutica debe ser analógica pues, así como el ser es analógico, así debe ser también la verdad, resolviendo de esta manera la situación paradójica. "Un modelo analógico de interpretación podrá embonar con un modelo analógico de metafísica, se necesitan el uno al otro" (Id. 103). Sin embargo,

Artículo que se encuentra en la Rev. Espíritu (Barcelona) 43.109 (1994). 
pensamos que la duda acerca de la fundamentación metafísica persiste, no así respecto de la ontológica.

El autor continúa indicando que una de las tareas de la metafísica es la tematización del ser y llevarlo al lenguaje; por eso "La hermenéutica conduce a la metafísica y la metafísica apoya a la hermenéutica" (Id. 110). Según esto, la tematización del mundo hace que la hermenéutica culmine en la metafísica. Con tales expresiones, lo que Beuchot sostiene es la relación de necesidad que debe darse entre la hermenéutica y la metafísica, y viceversa. Así lo expresa: "Hermenéutica y metafísica, pues, se condicionan mutuamente: la metafísica sólo es posible gracias a la hermenéutica que contextúa sus afirmaciones, y la hermenéutica sólo es posible si termina en una metafísica que a la vez fundamenta cualquier comprensión lingüística e histórica que se dé en ella" (Id. 113).

Pensamos que la insistencia en la necesidad de una fundamentación metafísica en el ejercicio hermenéutico no resuelve el problema, pues se observa el uso indistinto entre ontología y metafísica. En un subtítulo del texto que ahora comentamos: "Profundización argumentativa: la hermenéutica como apertura analógica a la metafísica", dice: "Y eso no lo puede hacer ya la hermenéutica; tiene que acudir a la ontología o metafísica" (Id. 114). La apelación se refiere a la existencia de un mundo real o ficticio, necesario para el acto de interpretación. Así, en varias ocasiones, en este inciso menciona la necesidad de que la hermenéutica se sustente en el carácter ontológico o metafísico. "Se requiere un modelo o paradigma analógico de la interpretación. Y esa analogia textus (analogía del texto) nos lleva a la analogia interpretationis (analogía de la interpretación) y ésta a la analogia entis (analogía del ente) y, por lo mismo, a la metafísica" (Id. 116-117).

Finalmente, cuando el autor habla de la relación de la hermenéutica con lo ontología dice que se trata de una fundamentación débil para evitar con ello posturas excluyentes y extremas tal y como se presentan en las interpretaciones univocistas y equivocistas que no favorecen las interpretaciones verdaderas.

En la obra de Gadamer, de manera especial en Verdad y método, se descubre la necesidad también de fundamentación ontológica pero no metafísica ¿Qué pasa pues con esta situación? 


\section{A manera de conclusión breve}

A través de este recorrido de encuentro y desencuentro entre la hermenéutica gadameriana y la hermenéutica analógica, hemos podido constatar que una de las conclusiones a las que llega Mauricio Beuchot respecto del uso y necesidad de la analogía hoy, sobremanera en el campo de la hermenéutica, se debe a que en este escenario filosófico surgen polaridades opuestas, que imposibilitan el diálogo y el acuerdo, siendo la analogía, precisamente, el recurso que posibilita la conducción por un nuevo y conveniente camino de encuentro, diálogo, convivencia, comprensión e interpretación. Coincidencia muy cercana a la propuesta de Gadamer.

- Como se ha podido advertir, ambas propuestas tienen tópicos comunes que las acercan, tales como el diálogo, la analogía, la convivencia, la mediación, etcétera; sin embargo, el problema focal entre la hermenéutica de Gadamer y la hermenéutica de Beuchot se centra en la fundamentación. Mientras para Gadamer se trata de una fundamentación ontológica, para Beuchot la fundamentación, indistintamente, puede ser metafísica u ontológica, dando lugar con ello a formas de ver e interpretar la realidad diferente y distante. El problema que con esto se provoca es saber si podemos entender la ontología y la metafísica en términos sinónimos.

- La responsabilidad en el diálogo exige éticamente aperturidad por parte de ambos dialogantes respecto del tema de que se trata, por dos razones básicas: primera, no dejarse llevar por enjuiciamientos prejuiciosos que impidan el desarrollo de la conversación; y, segunda, no orientar la conversación hacia el fin prefijado por uno de los dialogantes, lo que provocaría manipulación de la conversación. Siguiendo a Gadamer, como se ha comentado, el diálogo auténtico conlleva riesgos que deben asumirse, como por ejemplo no estar plenamente seguros de lo que pensamos y decimos; pero estos riesgos son menores con relación a la pretensión de sostener que hemos arribado a la última palabra que coincide con la nuestra'. Así, el inicio del diálogo está signado por cierta "inseguridad",

9 Tema que desarrolla ampliamente Gadamer, H.G. en su artículo "La continuidad de la historia y el instante de la existencia (1965)" en Verdad y método II. Sígueme: Salamanca, 1992, pp. 133-143. 
al no saber claramente hacia dónde vamos y también por no arribar a conclusiones definitivas.

- Entrar en una auténtica conversación no depende fundamentalmente de la disposición o apertura de los sujetos, sino de la ley de la "cosa misma" o del asunto de que se trata, que son los que dan lugar y orientan la conversación, provocándose el habla y la réplica. No es que la voluntad reservada o abierta del individuo no importe para la conversación, claro que sí; pero no depende de ella. Se necesita la conjugación de ambas cosas, pero se le debe conceder prioridad a la cosa misma, que es la guía de la conversación. Esta disposición subjetiva también está vinculada a una actitud ética: la de respeto a la naturaleza de la cosa. Esta orientación coincide con lo que Gadamer llama el "carácter medial" de la cosa misma.

- El diálogo no es más que el lenguaje realizado. Entender esta expresión exige remitirnos a la naturaleza del juego, es decir, impregnarnos de su espíritu: ligereza, libertad y felicidad del logro: así es la conversación. Disposición indispensable para los dialogantes que entran en el juego de la conversación hermenéutica.

\section{Bibliografía}

Aguilar Rivero, Mariflor y González Valerio, María Antonia (coords.). Gadamer y las Humanidades. Ontología, Lenguaje, Estética, Vol. I. México: UNAM, 2007.

Aguilar Rivero, Mariflor. Diálogo y alteridad. Trazos de la hermenéutica de Gadamer. México: UNAM, 2008.

Alcalá Campos, Raúl y Reyes Escobar, Jorge Armando (coords.). Gadamer y las Humanidades. Filosofía, Historia, Ciencias Sociales, Vol. II. México: UNAM, 2007.

Álvarez Balandra, Arturo. Hermenéutica analógica y procesos educativos. México: Número especial de Analogía, 2002.

Arenas-Dolz, Francisco y Gordo Pilar, Gemma (eds.). Márgenes de la interpretación. Diálogo, símbolo y analogía. Madrid-México: Plaza y Valdés, 2011.

Arias Sandí, M. La universalidad de la hermenéutica ¿Pretensión o rasgo fundamental? México: Fontamara, 2010.

Beuchot, Mauricio. Tratado de hermenéutica analógica. Hacia un nuevo modelo de interpretación. México: UNAM, 2015. 
Beuchot, M. Hermenéutica analógica y ontología. México: CIDHEM, 2013.

Beuchot, M. Hermenéutica analógica, religión e iconicidad. México: Démeter Ediciones, 2012.

Beuchot, M. Compendio de hermenéutica analógica. México: Torres Asociados, 2007.

Beuchot, M. Filosofía política. México: Torres Asociados, 2006a.

Beuchot, M. Puentes hermenéuticos hacia las humanidades y la cultura. México: EON/UIA, 2006b.

Beuchot, M. Interculturalidad y derechos humanos. México: UNAM/ Siglo XXI, 2005.

Beuchot, M., Vattimo, G. y Velasco Gómez, A. Hermenéutica analógica y Hermenéutica débil. México: UNAM, 2006.

Conde G., Napoleón. Hermenéutica analógica y formación docente. México: Torres Asociados, 2005.

Conde Gaxiona, N. (compilador). En torno a la hermenéutica analógica. México: Torres Asociados, 2010.

Gadamer, Hans-Georg. Estética y hermenéutica. Madrid: Tecnos 2001.

Gadamer, H-G. Hermenéutica de la modernidad. Conversaciones con Silvio Vietta. Madrid: Trotta 2004.

Gadamer, H-G. El último dios. La lección del siglo XX. Un diálogo filosófico con Riccardo Dottori. Barcelona: Anthropos/UAM (Cuajimalpa), 2010.

Gadamer, H-G. Verdad y método. Fundamentos de una hermenéutica filosófica. Salamanca: Sígueme, 1984.

Gadamer, H-G. Verdad y método II. Salamanca: Sígueme, 1992.

Gadamer, H-G. Antología. Salamanca: Sígueme, 2001.

Grondin, J. ¿Qué es la hermenéutica? Barcelona: Herder, 2008.

Lince Campillo, Rosa María y Amador Bech, Julio (coordinadores). Horizontes de interpretación. La hermenéutica y las ciencias humanas. Tomo I. México: UNAM, 2012.

Mardones, José María. El discurso religioso de la modernidad. Habermas y la religión. Barcelona: Anthropos/Universidad Iberoamericana, 1998.

Oliva Mendoza, Carlos. Hermenéutica del relajo y otros escritos sobre filosofía mexicana contemporánea. México: UNAM, 2013. 
Rivero Weber, P. (coordinadora). Cuestiones hermenéuticas. De Nietzsche a Gadamer. México: Itaca, 2006.

Solares, Blanca (ed.). Actualidad de la Hermenéutica Analógica. México: UNAM, 2014. 